\title{
Administración financiera de tesorería
}

\author{
Treasury financial administration Learning \\ María Guadalupe Castillo-Arroyo ${ }^{a}$, Beatriz Sauza-Ávila ${ }^{b}$ Claudia Beatriz Lechuga-Canto ${ }^{c}$
}

\begin{abstract}
:
Companies face to solve problems related to the proper use of cash, consisting of managing it efficiently, there are mainly two dilemmas which are to pay on time and form to the suppliers or choose to cover the credit after the terms granted, without However, the latter means a risk. Considering that in the future sellers can stop supplying the product and this could put the company in serious trouble, on the other hand when the papers are invested and the organization is the one that sells the goods and services it requires that they be paid as soon as possible facing similarly to risk situations. It is for these reasons that those who control finances must use various strategies that allow them to make appropriate decisions to be effective use of financial resources.
\end{abstract}

\section{Keywords:}

Cash, suppliers, customers.

\section{Resumen:}

Las empresas se enfrentan a resolver problemas relacionados con el uso adecuado del efectivo, consistiendo en administrarlo eficientemente, existiendo principalmente dos disyuntivas las cuales son en pagar en tiempo y forma a los proveedores u optar por cubrir el crédito posterior a los plazos que otorgan, sin embargo, esto último significa un riesgo. Considerando que en un futuro los vendedores pueden dejar de suministrar el producto y esto podría poner en graves problemas a la empresa, por otra parte cuando los papeles se invierten y la organización es quien vende los bienes y servicios requiere que se le paguen lo más pronto posible enfrentándose de igual manera a situaciones de riesgo. Es por estos motivos que quienes controlan las finanzas deben usar diversas estrategias que les permitan tomar adecuadas decisiones para ser uso eficaz de los recursos financieros.

\section{Palabras Clave:}

Efectivo, proveedores, clientes.

\section{Introducción}

El presente mapa conceptual tiene como objetivo principal introducir a los alumnos en el conocimiento general del uso adecuado del efectivo, muestra las formas en que se debe controlar la caja o tesorería, el manejo de los inventarios y la las cuentas por cobrar.

\footnotetext{
a Autor de Correspondencia, Universidad Autónoma del Estado de Hidalgo, Escuela Superior Ciudad Sahagún, Email: mariaguadalupe.castillo.uaeh@gmail.com

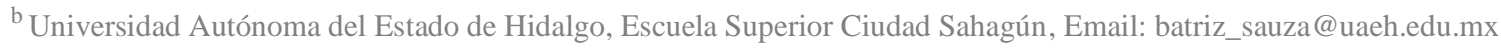

${ }^{\mathrm{c}}$ Universidad Autónoma del Estado de Hidalgo, Escuela Superior Ciudad Sahagún, Email: claublc@uaeh.edu.mx
} 


\section{Descripción}

Con relación a la caja, se debe tomar en cuenta cual es el dinero en efectivo del que debe disponerse para cumplir los compromisos a corto plazo para ello existen diferentes métodos para su cálculo como por ejemplo la caja óptima, cálculo de demora de pagos, método Baumol entre otras, en cuanto al manejo inventarios se pueden utilizar las técnicas de punto económico de reorden, cantidad económica óptima, costo por mantener, costo por ordenar, lo relacionado con clientes las herramientas que se pueden utilizar son: crédito necesario para un cliente nuevo, crédito necesario para un cliente antiguo, crédito necesario para cliente estacionales. 1

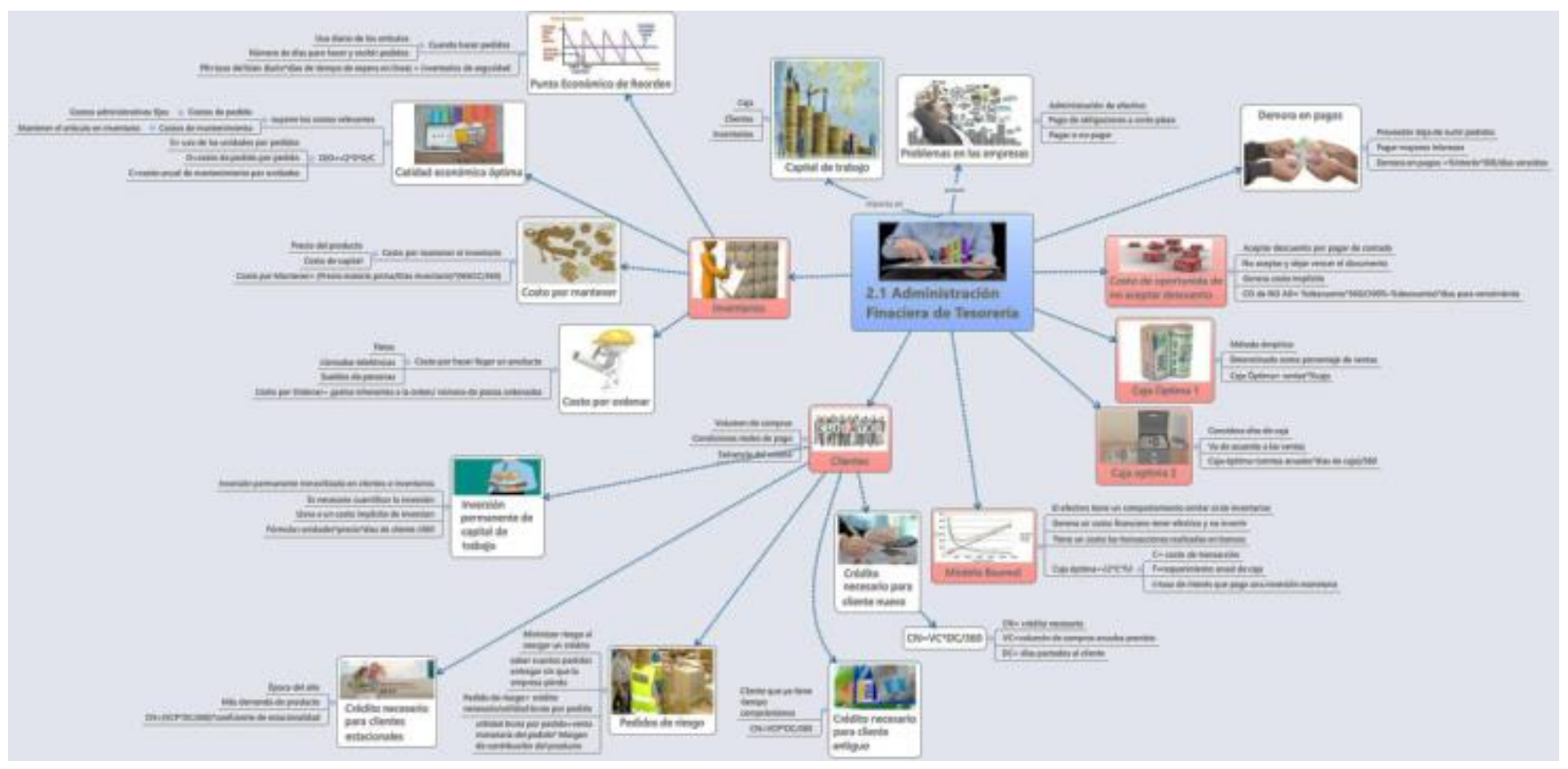

Figura 1. Administración financiera de tesorería

\section{Referencias}

1] González, S. J. (2010). Manual de fórmulas financieras una herramienta para el mundo actual. México: Alfaomega. 